\title{
Heart Rate, Body Temperature and Physical Activity Are Variously Affected During Insulin Treatment in Alloxan-Induced Type 1 Diabetic Rat
}

\author{
F. C. HOWARTH ${ }^{1}$, M. JACOBSON ${ }^{2}$, M. SHAFIULLAH ${ }^{3}$, M. LJUBISAVLJEVIC ${ }^{1}$, \\ E. ADEGHATE ${ }^{4}$
}

${ }^{1}$ Department of Physiology, Faculty of Medicine \& Health Sciences, United Arab Emirates University, Al Ain, UAE, ${ }^{2}$ Biomedical Engineering, Higher Colleges of Technology, Abu Dhabi, UAE, ${ }^{3}$ Department of Pharmacology, Faculty of Medicine \& Health Sciences, United Arab Emirates University, Al Ain, UAE, ${ }^{4}$ Department of Anatomy, Faculty of Medicine \& Health Sciences, United Arab Emirates University, Al Ain, UAE

Received February 23, 2010

Accepted July 2, 2010

On-line October 15, 2010

\section{Summary}

Diabetes mellitus is associated with a variety of cardiovascular complications including impaired cardiac muscle function. The effects of insulin treatment on heart rate, body temperature and physical activity in the alloxan (ALX)-induced diabetic rat were investigated using in vivo biotelemetry techniques. The electrocardiogram, physical activity and body temperature were recorded in vivo with a biotelemetry system for 10 days before ALX treatment, for 20 days following administration of ALX $(120 \mathrm{mg} / \mathrm{kg}$ ) and thereafter, for 15 days whilst rats received daily insulin. Heart rate declined rapidly after administration of ALX. Pre-ALX heart rate was $321 \pm 9$ beats per minute, falling to $285 \pm 12$ beats per minute $15-20$ days after ALX and recovering to $331 \pm 10$ beats per minute 5-10 days after commencement of insulin. Heart rate variability declined and $P Q, Q R S$ and $Q T$ intervals were prolonged after administration of ALX. Physical activity and body temperature declined after administration of ALX. Pre-ALX body temperature was $37.6 \pm 0.1^{\circ} \mathrm{C}$, falling to $37.3 \pm 0.1{ }^{\circ} \mathrm{C} 15-20$ days after $\mathrm{ALX}$ and recovering to $37.8 \pm 0.1{ }^{\circ} \mathrm{C}$ 5-10 days after commencement insulin. ALX-induced diabetes is associated with disturbances in heart rhythm, physical activity and body temperature that are variously affected during insulin treatment.

\section{Key words}

Heart rate - Physical activity • Body temperature • Diabetes mellitus • Alloxan • Insulin

\section{Corresponding author}

Frank Christopher Howarth, Department of Physiology, Faculty of Medicine \& Health Sciences, United Arab Emirates University, P.O. Box 17666, Al Ain, United Arab Emirates. Fax: +9713-7671866. E-mail: chris.howarth@uaeu.ac.ae

\section{Introduction}

Cardiovascular disease is a major cause of morbidity and mortality in diabetic patients and hearts of diabetic patients are in a compromised condition (Julien 1997, Dhalla et al. 1985). Diabetic patients show a higher incidence of cardiac arrhythmias, including ventricular fibrillation and sudden death. The electrocardiogram of diabetic patients may show a number of abnormalities including alterations to the QT interval, which reflects the total duration of ventricular myocardial depolarisation and repolarisation, and $\mathrm{T}$ wave (Casis and Echevarria 2004, Veglio et al. 2004, Veglio et al. 2002, Veglio et al. 2000). Various abnormalities including autonomic dysfunction, defective glucose metabolism, vascular disease, myocardial ischemia, cardiac fibrosis, cardiac hypertrophy may play a role in the pathogenesis of electrical disturbances in diabetic heart. Treatment of young adult rats with alloxan (2,4,5,6tetraoxypyrimidine; 5,6-dioxyuracil; ALX) produces a diabetic state that is characterized by poor weight gain, 
polydipsia, polyuria, polyphagia, dyslipidemia, hypoinsulinaemia and hyperglycaemia (Wexler and Lutmer 1975, Altura et al. 1981). Experiments in ALXinduced diabetic rabbits have demonstrated that prolonged QT interval is partly attributed to alterations in various $\mathrm{K}^{+}$and $\mathrm{Ca}^{2+}$ currents including the transient outward $\mathrm{K}(+)$ current, the rapid and slow delayed rectifier $\mathrm{K}(+)$ current and L-type $\mathrm{Ca}^{2+}$ current (Zhang et al. 2007, Lengyel et al. 2008). Previous in vivo biotelemetry studies have reported the effects of short- and long-term streptozotocin (STZ)-induced diabetes on heart rate, body temperature and physical activity. Following STZ treatment heart rate, body temperature and physical activity are reduced and there is a recovery of heart rate and body temperature during insulin treatment (Howarth et al. 2005a, Howarth et al. 2005b, Howarth et al. 2006). The aim of this study was to utilize in vivo biotelemetry techniques to investigate the effects of insulin treatment on heart rate, body temperature and physical activity in the ALX-induced diabetic rat in conscious, unrestrained animals and compare the effects with those reported in the STZ-induced diabetic rat.

\section{Methods}

\section{Telemetry system}

Previously described biotelemetry techniques were used to acquire heart biopotential, physical activity and body temperature (Howarth et al. 2006). The system comprised the transmitter devices (TA11CTA-F40, Data Sciences Int., USA), the receivers (RPC-1), a data exchange matrix $(20 \mathrm{CH})$ and a personal computer for system configuration, control, acquisition, and data storage. The transmitter devices were surgically implanted in 6 male Wistar rats $(445.7 \pm 29.2 \mathrm{~g})$ under general anaesthesia (sodium pentobarbitone, $45 \mathrm{mg} / \mathrm{kg}$, intraperitoneal). The devices were inserted into the peritoneal cavity and electrodes from the transmitter were arranged in Einthoven bipolar - Lead II configuration with one electrode connected to the right foreleg and one to the left hind leg. In addition to ECG the implant transmits core temperature. Physical activity was assessed by measuring changes in the animal's transmitter signal strength. Specifically, the transmitter signal strength was sampled at $64 \mathrm{~Hz}$ and calibrated to counts per minute. When the animal changes position, the corresponding transmitter signal strength is changed, which results in a change in counts per minute. Low counts indicate reduced physical activity in the animal (Howarth et al.
2006). After recovery from surgery, transmitters were then switched on by activation of a magnetic switch, located in the transmitter device, with a permanent magnet brought into close proximity to the animal. Data recording was started 5 days before the induction of diabetes and continued after injection of ALX and during insulin treatment. Ethical approval for the project was obtained from the Faculty of Medicine \& Health Sciences Ethics Committee for Animal Research.

\section{Induction of diabetes and insulin treatment}

After 5 days of data acquisition, diabetes was induced in the 6 Wistar rats by a single intraperitoneal injection of ALX (120 mg/kg body weight; Sigma, St Louis, MO, USA) (Wexler and Lutmer 1975, Zhang et al. 2007, Altura et al. 1981). The ALX was dissolved in a citrate buffer solution $(0.1 \mathrm{~mol} / 1 \mathrm{citric}$ acid, $0.1 \mathrm{~mol} / 1$ sodium citrate; $\mathrm{pH} 4.5$ ). Insulin (Lantus, Sanofi-Aventis, France) treatment (2-5 Units per day, subcutaneous) was started on Day 21 after ALX and continued for a period of 15 days. Non-fasting blood glucose was measured 6 and 24 hours after insulin treatment. Blood was obtained from a small knick in the tail and blood glucose was measured with a glucometer (One Touch Ultra, Lifescan Inc., USA).

\section{Data collection and analysis}

Electrocardiogram, physical activity and body temperature data were collected 5 minutes per hour per animal, 24 hours per day, and 7 days per week for the duration of the study. Data recording commenced 5 days before the administration of ALX and continued thereafter for the remainder of the experimental period. From the collected electrocardiographic data, secondary physiological measurements were determined including the average 5-minute heart rate, heart rate variability and PQ, QRS and QT-intervals. Statistical comparisons were made between group day values using paired t-test and p-values less than 0.05 were considered significant.

\section{Results}

\section{General characteristics of the ALX-induced diabetic rat}

Mean bodyweight and blood glucose values at the start of the experiment before ALX treatment were $445.7 \pm 29.2 \mathrm{~g}$ and $105.0 \pm 3.2 \mathrm{mg} / \mathrm{dl}(\mathrm{n}=6)$, respectively. Mean bodyweight and blood glucose immediately before commencement of insulin treatment were $396.2 \pm 28.4 \mathrm{~g}$ and $425.8 \pm 74.4 \mathrm{mg} / \mathrm{dl}(\mathrm{n}=6)$, respectively. During the 
15 days of insulin treatment the mean blood glucose recorded 6 hours after insulin treatment was $61.3 \pm 14.1$ $\mathrm{mg} / \mathrm{dl}$.

\section{Heart rate}

Heart rate was determined from the 5-minute average of all normal R-wave to R-wave intervals in the electrocardiogram. The effects of ALX treatment on heart rate are shown in Fig. 1a and 1b. Heart rate fell rapidly and dramatically after administration of ALX (Fig. 1a). Before ALX treatment the heart rate was $321 \pm 9$ beats per minute, falling significantly $(\mathrm{p}<0.01)$ to $285 \pm 12$ beats per minute 15-20 days after ALX. Heart rate recovered and exceeded pre-ALX levels 5-10 days after commencement of insulin (331 \pm 10 beats per minute) (Fig. 1b).
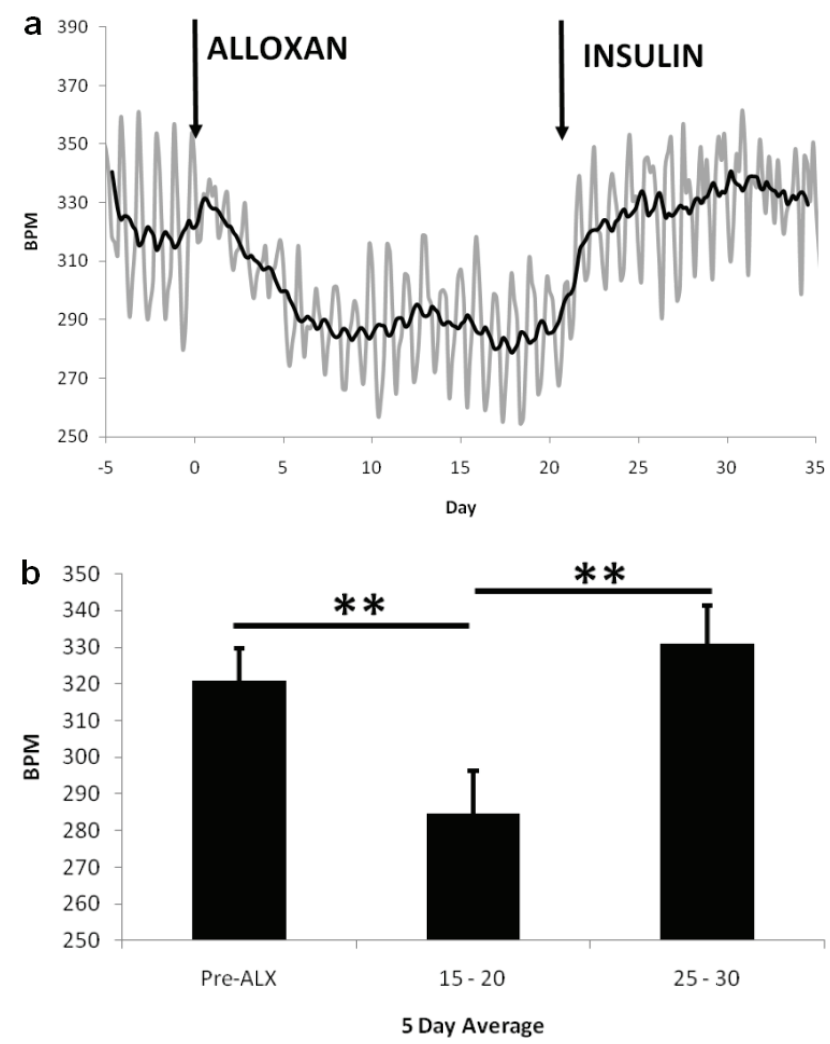

Fig. 1. Effects of ALX-induced diabetes on heart rate. (a) Gray line displays the hourly heart rate group mean and the black line displays the $24 \mathrm{hr}$ group mean. (b) Group mean heart rate with standard error bars for pre-ALX, 15-20 days after ALX, and 5-10 days (Day 25-30) of insulin treatment. Data are mean \pm SEM, $\mathrm{n}=6$ rats. Statistical significance $* * \mathrm{p}<0.01$.

\section{Heart rate variability}

Heart rate variability was computed as the standard deviation (STD) of the average of normal-tonormal beats (SDANN). Specifically, the SDANN was computed by first determining the 5-minute, average heart rate for each animal every hour. Then, the STD of 12 previous heart rate averages and 12 subsequent heart rate averages was computed in order to determine the 24-hour heart rate variability. The effects of ALX treatment on SDANN defined heart rate variability are shown in Figures $2 \mathrm{a}$ and $2 \mathrm{~b}$. Heart rate variability before ALX treatment was $28 \pm 2$ beats per minute, falling modestly to $23 \pm 3$ beats per minute 15-20 days after ALX. Insulin treatment for 5-10 days did not significantly ( $>0.05)$ improve heart rate variability $(24 \pm 4$ beats per minute) (Fig. 2b).


Fig. 2. Effects of ALX-induced diabetes on heart rate variability. (a) Gray line displays the hourly HRV group mean and the black line displays the $24 \mathrm{hr}$ group mean. (b) Group mean HRV with standard error bars for pre-ALX, 15-20 days after ALX, and 5-10 days (Day 25-30) of insulin treatment. Data are mean \pm SEM, $\mathrm{n}=6$ rats.

\section{Electrocardiogram}

The effects of ALX on PQ interval are shown in Figures $3 \mathrm{a}$ and $3 \mathrm{~b}$. Before ALX treatment the PQ interval was $(51 \pm 1 \mathrm{msec})$. The PQ interval was modestly prolonged following ALX (52 $\pm 2 \mathrm{msec})$ and recovered during insulin treatment $(49 \pm 2 \mathrm{msec})$ (Fig. 3b). The effects of ALX on QRS interval are shown in Figures $3 \mathrm{c}$ and $3 \mathrm{~d}$. Before ALX treatment the QRS interval was $14.4 \pm 0.4 \mathrm{msec}$. ALX modestly prolonged 

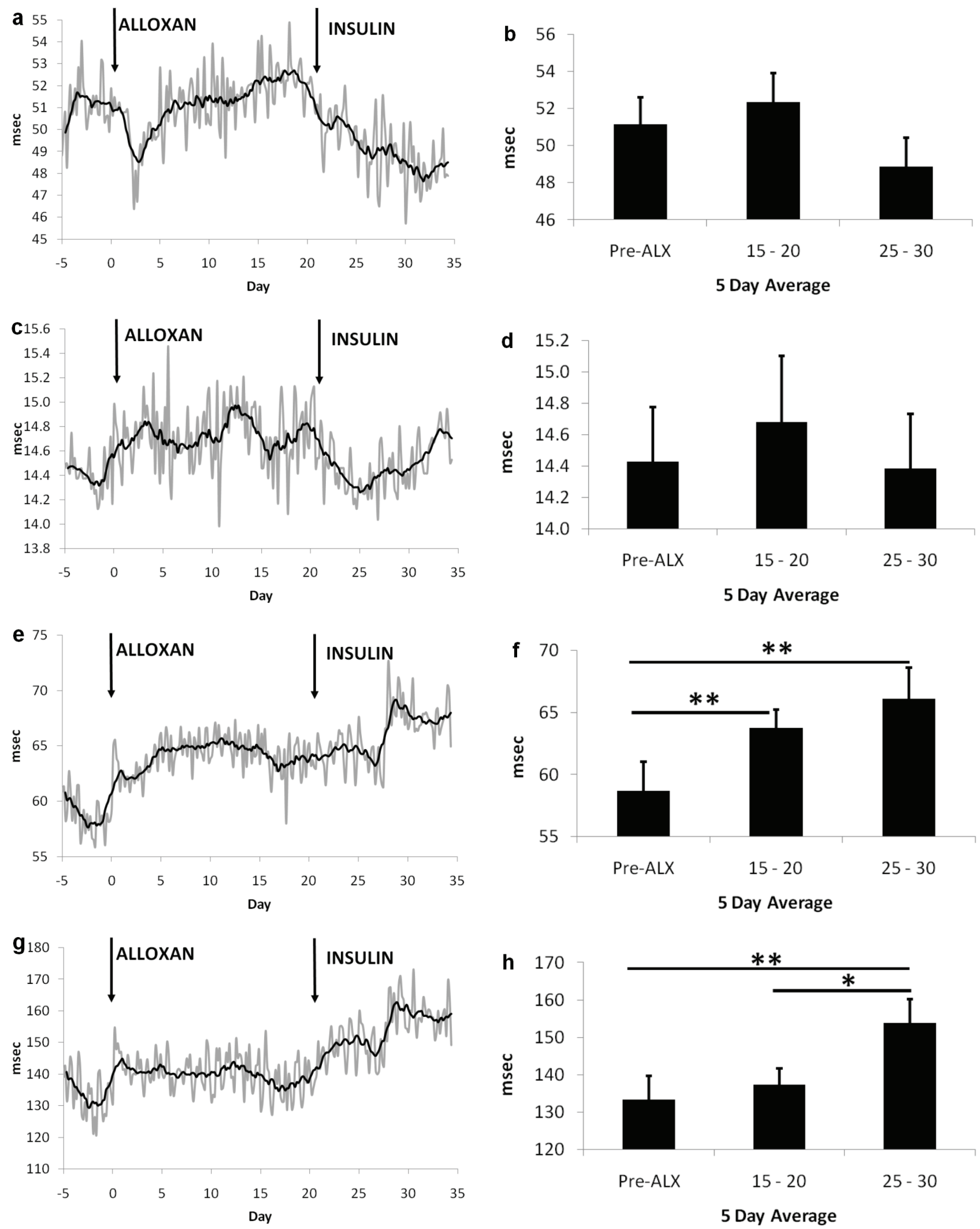

Fig. 3. Effects of ALX-induced diabetes on the electrocardiogram. (a, c, e, g) Gray line displays the hourly group mean $P Q, Q R S, Q T$ and corrected QT intervals, respectively, and black line displays the $24 \mathrm{hr}$ group mean. (b, d, f, h) Group mean of PQ, QRS, QT and corrected QT intervals, respectively, with associated standard error bars for pre-ALX, 15-20 days after ALX, and 5-10 days (Day 25-30) following insulin treatment. Data are mean $\pm S E M, n=6$ rats. Statistical significance $* p<0.05$ and $* * p<0.01$. 

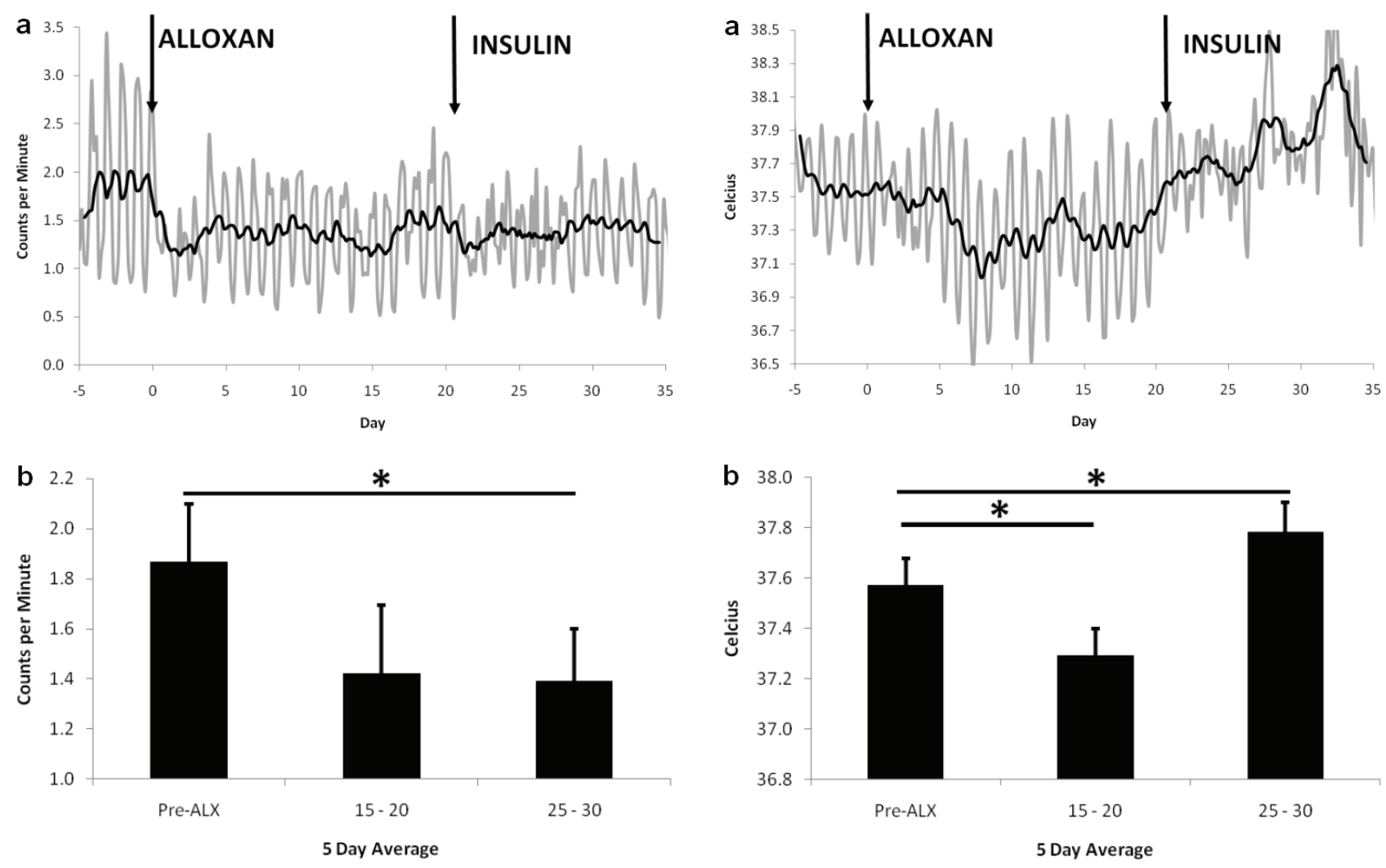

Fig. 4. Effects of ALX-induced diabetes on physical activity. (a) Gray line displays the hourly group mean of physical activity and black line displays the $24 \mathrm{hr}$ group mean. (b) Group mean of physical activity with standard error bars for pre-ALX, 15-20 days after ALX, and 5-10 days (Day 25-30) following insulin treatment. Data are mean \pm SEM, $n=6$ rats. Statistical significance $* p<0.05$.

(14.7 $\pm 0.4 \mathrm{msec})$ and insulin normalized $(14.4 \pm 0.3 \mathrm{msec})$ the QRS interval (Fig. 3d). The effects of ALX on QT interval are shown in Fig. 3e and 3f. Before ALX treatment the QT interval was $59 \pm 2 \mathrm{msec}$. ALX significantly $(\mathrm{p}<0.01)$ prolonged $(64 \pm 2 \mathrm{msec})$ and QT was further prolonged during insulin treatment $(66 \pm 2$ msec) (Fig. 3f). The effects of ALX on corrected QT interval (Bazett) are shown in Figures $3 \mathrm{~g}$ and $3 \mathrm{~h}$. Before ALX treatment the corrected QT was $133 \pm 6$ msec. ALX modestly prolonged $(137 \pm 4 \mathrm{msec})$ and insulin further prolonged (154 $\pm 6 \mathrm{msec}$ ) corrected QT interval (Fig. 3h).

\section{Physical activity}

Physical activity was assessed by measuring changes in the animal's transmitter signal strength. Specifically, the transmitter signal strength was sampled at $64 \mathrm{~Hz}$ and calibrated to counts per minute. When the animal changes its position, the corresponding transmitter signal strength is changed, which results in a change in counts per minute. Low counts indicate reduced physical activity in the animal. The effects of ALX on physical activity are shown in Figures $4 \mathrm{a}$ and $4 \mathrm{~b}$. Before ALX

Fig. 5. Effects of ALX-induced diabetes on body temperature. (a) Gray line displays the hourly mean of body temperature and black line displays the $24 \mathrm{hr}$ group mean. (b) Group mean of physical activity with standard error bars for pre-ALX, 15-20 days after ALX, and 5-10 days (Day 25-30) following insulin treatment. Data are mean \pm SEM, $n=6$ rats. Statistical significance $* p<0.05$.

treatment physical activity was $1.87 \pm 0.23$ counts per minute, falling modestly to $1.42 \pm 0.27$ counts per minute 15-20 days after ALX. Physical activity was not improved by insulin ( $1.39 \pm 0.21$ counts per minute) (Fig. 4b).

\section{Body temperature}

In addition to the electrocardiogram the implant transmits core temperature. Similar to the heart rate, the temperature was measured and recorded each hour. The effects of ALX treatment on body temperature are shown in Figures $5 \mathrm{a}$ and $5 \mathrm{~b}$. The 24-hour computed average body temperature declined after administration of ALX. Before ALX treatment the body temperature was $37.6 \pm 0.1{ }^{\circ} \mathrm{C}$, falling significantly $(\mathrm{p}=0.01)$ to $37.3 \pm 0.1^{\circ} \mathrm{C}$ 15-20 days after ALX. Body temperature recovered and exceeded pre-ALX levels 5-10 days after commencement of insulin $\left(37.8 \pm 0.1{ }^{\circ} \mathrm{C}\right)$ (Fig. 5b). The combined effects of ALX on heart rate, body temperature and physical activity data are shown in Figure 6. Following ALX treatment there was a decline in heart rate, body temperature and physical activity. The decline of physical 
activity occurred at the highest rate and this was followed by a decline in heart rate and body temperature which took place more-or-less in parallel. Heart rate and body temperature recovered and physical activity remained depressed during insulin treatment.



Fig. 6. Comparative effects of ALX-induced diabetes on heart rate, body temperature and physical activity by display of percent change. Though changes in heart rate and body temperatures drop and recover as similar events, reduction in physical activity occurs before and does not fully recover during insulin treatment. Data are mean $\pm S E M, n=6$ rats.

\section{Discussion}

This study employed in vivo biotelemetry techniques to investigate the effects of ALX-induced diabetes and insulin treatment on heart rate, body temperature and physical activity in unrestrained, conscious animals.

Diabetes was confirmed by a 4-fold increase in blood glucose following ALX treatment. Administration of insulin began 21 days after ALX and was continued for the remainder of the study. The dose of insulin was varied between 2-5 Units per day depending on blood glucose levels which were measured on a daily basis, 6 and 24 hours after insulin treatment. The choice of insulin (Lantus, Sanofi-Aventis, France) and the treatment protocol were effective in reducing blood glucose levels to approx. $60 \mathrm{mg} / \mathrm{dl}$ at 6 hours after insulin compared to pre-insulin blood glucose levels of $430 \mathrm{mg} / \mathrm{dl}$.

Heart rate, measured in vivo with a biotelemetry system, was reduced rapidly and dramatically following ALX treatment. Insulin treatment not only reversed the effects of ALX but also increased heart rate compared to pre-ALX levels. A previous in vivo biotelemetry study also demonstrated a rapid reduction in heart rate following administration of the diabetogenic agent streptozotocin (STZ) and a biphasic recovery of heart rate during insulin treatment (Howarth et al. 2006).

Reductions in rate have also been demonstrated in vitro for example in isolated heart and in spontaneously-beating atria following ALX treatment (Garber et al. 1983, Ozcelikay et al. 1993, Kulkarni et al. 2002, Karasu et al. 1990). These data suggest that a mechanism that is intrinsic to the heart may partly underlie the bradycardia observed in ALX-induced diabetic heart. It should be noted however, that some studies have reported no effects of ALX on resting heart rate (Lee et al. 1989, Zola et al. 1988). A recent study demonstrated that perfusion of the isolated heart with ALX caused a reduction in heart rate suggesting that ALX may have direct actions on heart function that are not attributable to diabetes mellitus (Salem et al. 2009).

The PQ interval was not significantly altered by ALX treatment a finding that is consistent with a previous study performed in ALX-induced diabetic dogs (Lengyel et al. 2007). Interestingly, a study in type 1 diabetic patients with cardiovascular autonomic neuropathy, demonstrated a shorter PQ interval suggesting an impairment of atrio-ventricular conduction velocity (Krahulec et al. 2002). Consistent with the reduction in heart rate ALX treatment caused a prolongation of the QT interval which is a reflection of the total duration of ventricular myocardial depolarisation and repolarisation. Some previous studies have demonstrated prolongation of action potential duration in papillary muscle preparations from ALX-induced diabetic heart which would be consistent with prolonged QT (Chen et al. 2004, Sauviat and Feuvray 1986). The prolonged QT may be partly attributed to alterations in various $\mathrm{K}^{+}$and $\mathrm{Ca}^{2+}$ currents including the transient outward $\mathrm{K}(+)$ current, the rapid and slow delayed rectifier $\mathrm{K}(+)$ current and L-type $\mathrm{Ca}^{2+}$ current (Zhang et al. 2007, Lengyel et al. 2008).

Heart rate variability, an indicator of sympathovagal modulation of heart function (Ferrari et al. 1987, Bootsma et al. 1994), was modestly reduced in ALX treated rats. Studies in diabetic rat following shortand long-term STZ treatment have also demonstrated reductions in heart rate variability and other related indices (Howarth et al. 2005a, Howarth et al. 2005b, Fazan et al. 1999, Lo et al. 2002) suggesting that disturbances in autonomic drive to the heart may also partly underlie the reduction in heart rate observed in the ALX-induced diabetic rat.

Following ALX treatment there was a rapid 
decline in physical activity and this was followed by a decline in heart rate and body temperature which took place more-or-less in parallel. Heart rate and body temperature recovered and physical activity remained depressed during insulin treatment. Hypothyroidism is a widely reported feature of ALX-induced diabetes (Kulkarni et al. 2002, Karasu et al. 1990, Vadlamudi and McNeill 1984, Garber and Neely 1983). Experimentally induced hypothyroidism in rats causes impairments in diastolic and systolic function and a reduced heart rate (Galinanes et al. 1994, Seppet et al. 1993, Yin et al. 1992, Balkman et al. 1992, McDonough et al. 1987). On the other hand hyperthyroidism is associated with cardiac hypertrophy, tachycardia and elevated myocardial contractility (Wheatley et al. 1990, Lortet et al. 1989). Baseline isolated atrial rate is lower in hypothyroid and higher in hyperthyroid compared to euthyroid rats (Turner and Shenfield 1980). Hyperthyroid state produced by administration of triiodothyrinine is characterized by an increase in heart rate and cardiac output (Zierhut and Zimmer 1989). The duration of action potential recorded from single papillary muscle cells from 60 day old rats, thyroidectomised at weaning, is longer than in preparations from euthyroid rats. Treatment of thyroidectomised rats with triiodothyrinine restores the values of action potential duration present in euthyroid animals (Di Meo et al. 1991). Taken together these findings may suggest, subject to measurement of thyroid hormone, that alterations in thyroid hormone, and its calorigenic heat promoting actions, may partly underlie the reduction in body temperature and heart rate following ALX treatment.

Physical activity was reduced following ALX treatment. Reduced physical activity may partly underlie reduced heart rate. Insulin treatment had no significant effect on physical activity but it did normalize heart rate. The mechanism(s) underlying ALX-induced hypoactivity will require further investigation. However, it is possible that ALX may have caused irreparable damage to some aspect of glucose uptake and utilization that subsequently prevent the generation of full energy balance required for optimal physical activity. Since calcium is crucial to muscle contraction and physical activity, the disturbance in calcium homeostasis caused by ALX (Salem et al. 2009) may take a longer time to be corrected even after initial insulin treatment and thus a possible contributing factor in the development of reduced physical activity in ALX-treated rats.

In conclusion ALX-induced diabetes is associated with disturbances in heart rhythm, physical activity and body temperature that are variously affected during insulin treatment. Alterations in autonomic drive and electrical conduction may partly underlie heart rhythm disturbances in ALX-induced diabetic rat heart. Effects attributed to ALX-induced diabetes may be complicated by associated hypothyroidism.

\section{Conflict of Interest}

There is no conflict of interest.

\section{Acknowledgements}

This project was supported by an Individual Grant from the United Arab Emirates University, Al Ain, United Arab Emirates.

\section{Abbreviations}

ALX, Alloxan, STD, Standard deviation, SDANN, Standard deviation of the average of normal-to-normal beats.

\section{References}

ALTURA BM, LUM G, TURLAPATY PD, ALTURA BT: Sequential changes in serum glucose, triglycerides and cholesterol in aging of normal and alloxan-diabetic rats. Experientia 37: 224-226, 1981.

BALKMAN C, OJAMAA K, KLEIN I: Time course of the in vivo effects of thyroid hormone on cardiac gene expression. Endocrinology 130: 2001-2006, 1992.

BOOTSMA M, SWENNE CA, VAN BOLHUIS HH, CHANG PC, CATS VM, BRUSCHKE AV: Heart rate and heart rate variability as indexes of sympathovagal balance. Am J Physiol 266: H1565-H1571, 1994.

CASIS O, ECHEVARRIA E: Diabetic cardiomyopathy: electromechanical cellular alterations. Curr Vasc Pharmacol 2: 237-248, 2004.

CHEN ZQ, HU S J, XIA Q, SHEN YL: [Effect of adenosine on electrophysiological changes of ventricular myocardium in rats with experimental diabetes]. (in Chinese) Zhejiang Da Xиe Xие Bao Yi Xиe Ban 33: 437$442,2004$. 
DHALLA NS, PIERCE GN, INNES IR, BEAMISH RE: Pathogenesis of cardiac dysfunction in diabetes mellitus. Can J Cardiol 1: 263-281, 1985.

DI MEO S, DE MARTINO RP, DE LEO T: Thyroid state and electrical properties of rat papillary muscle fibres. Arch Int Physiol Biochim Biophys 99: 377-383, 1991.

FAZAN R Jr, DIAS DSV, BALLEJO G, SALGADO HC: Power spectra of arterial pressure and heart rate in streptozotocin-induced diabetes in rats. J Hypertens 17: 489-495, 1999.

FERRARI AU, DAFFONCHIO A, ALBERGATI F, MANCIA G: Inverse relationship between heart rate and blood pressure variabilities in rats. Hypertension 10: 533-537, 1987.

GALINANES M, SMOLENSKI RT, HADDOCK PS, HEARSE DJ: Early effects of hypothyroidism on the contractile function of the rat heart and its tolerance to hypothermic ischemia. J Thorac Cardiovasc Surg 107: 829-837, 1994.

GARBER DW, EVERETT AW, NEELY JR: Cardiac function and myosin ATPase in diabetic rats treated with insulin, T3, and T4. Am J Physiol 244: H592-H598, 1983.

GARBER DW, NEELY JR: Decreased myocardial function and myosin ATPase in hearts from diabetic rats. Am $J$ Physiol 244: H586-H591, 1983.

HOWARTH FC, JACOBSON M, NASEER O, ADEGHATE E: Short-term effects of streptozotocin-induced diabetes on the electrocardiogram, physical activity and body temperature in rats. Exp Physiol 90: 237-245, 2005a.

HOWARTH FC, JACOBSON M, SHAFIULLAH M, ADEGHATE E: Long-term effects of streptozotocin-induced diabetes on the electrocardiogram, physical activity and body temperature in rats. Exp Physiol 90: 827-835, $2005 b$.

HOWARTH FC, JACOBSON M, SHAFIULLAH M, ADEGHATE E: Effects of insulin treatment on heart rhythm, body temperature and physical activity in streptozotocin-induced diabetic rat. Clin Exp Pharmacol Physiol 33: 327-331, 2006.

JULIEN J: Cardiac complications in non-insulin-dependent diabetes mellitus. J Diabetes Complications 11: 123-130, 1997.

KARASU C, OZTURK Y, ALTAN N, YILDIZOGLU-ARI N, IKIZLER C, ALTAN VM: Thyroid hormones mediated effect of insulin on alloxan diabetic rat atria. Gen Pharmacol 21: 735-740, 1990.

KRAHULEC B, MIKES Z, BALAZOVJECH I: The effect of cardiovascular autonomic neuropathy on resting ECG in type 1 diabetic patients. Bratisl Lek Listy 103: 54-58, 2002.

KULKARNI JS, METHA AA, SANTANI DD, GOYAL RK: Effects of chronic treatment with cromakalim and glibenclamide in alloxan-induced diabetic rats. Pharmacol Res 46: 101-105, 2002.

LEE JH, KONARSKA M, MCCARTY R: Physiological responses to acute stress in alloxan and streptozotocin diabetic rats. Physiol Behav 45: 483-489, 1989.

LENGYEL C, VIRAG L, KOVACS PP, KRISTOF A, PACHER P, KOCSIS E, KOLTAY ZM, NANASI PP, TOTH M, KECSKEMETI V, PAPP JG, VARRO A, JOST N: Role of slow delayed rectifier $\mathrm{K}^{+}$-current in QT prolongation in the alloxan-induced diabetic rabbit heart. Acta Physiol (Oxf) 192: 359-368, 2008.

LENGYEL C, VIRÁG L, BÍRÓ T, JOST N, MAGYAR J, BILICZKI P, KOCSIS E, SKOUMAL R, NÁNÁSI PP, TÓTH M, KECSKEMÈTI V, PAPP JG, VARRÓ A: Diabetes mellitus attenuates the repolarization reserve in mammalian heart. Cardiovasc Res 73: 512-520, 2007.

LO GP, CAREDDU A, MAGNI G, QUAGLIATA T, PACIFICI L, CARMINATI P: Autonomic neuropathy in streptozotocin diabetic rats: effect of acetyl-L-carnitine. Diabetes Res Clin Pract 56: 173-180, 2002.

LORTET S, ZIMMER HG, ROSSI A: Inotropic response of the rat heart during development and regression of triiodothyronine-induced hypertrophy. J Cardiovasc Pharmacol 14: 707-712, 1989.

MCDONOUGH KH, CHEN V, SPITZER JJ: Effect of altered thyroid status on in vitro cardiac performance in rats. Am J Physiol 252: H788-H795, 1987.

OZCELIKAY AT, YIDIZOGLU-ARI N, OZUARI A, OZTURK Y, ALTAN VM: The effect of vanadate on alloxandiabetic rat atria. Diabetes Res Clin Pract 19: 189-194, 1993.

SALEM KA, KOSANOVIC M, QURESHI A, LJUBISAVLJEVIC M, HOWARTH FC: The direct effects of streptozotocin and alloxan on contractile function in rat heart. Pharmacol Res 59: 235-241, 2009. 
SAUVIAT MP, FEUVRAY D: Electrophysiological analysis of the sensitivity to calcium in ventricular muscle from alloxan diabetic rats. Basic Res Cardiol 81: 489-496, 1986.

SEPPET EK, KOLAR F, DIXON IM, HATA T, DHALLA NS: Regulation of cardiac sarcolemmal $\mathrm{Ca}^{2+}$ channels and $\mathrm{Ca}^{2+}$ transporters by thyroid hormone. Mol Cell Biochem 129: 145-159, 1993.

TURNER CW, SHENFIELD GM: The effect of thyroid dysfunction on the chronotropic response to noradrenaline. Eur J Pharmacol 68: 295-303, 1980.

VADLAMUDI RV, MCNEILL JH: Effect of experimental diabetes on isolated rat heart responsiveness to isoproterenol. Can J Physiol Pharmacol 62: 124-131, 1984.

VEGLIO M, BRUNO G, BORRA M, MACCHIA G, BARGERO G, D'ERRICO N, PAGANO GF, CAVALLO-PERIN P: Prevalence of increased QT interval duration and dispersion in type 2 diabetic patients and its relationship with coronary heart disease: a population-based cohort. J Intern Med 251: 317-324, 2002.

VEGLIO M, CHINAGLIA A, CAVALLO PP: The clinical utility of QT interval assessment in diabetes. Diabetes Nutr Metab 13: 356-365, 2000.

VEGLIO M, CHINAGLIA A, CAVALLO-PERIN P: QT interval, cardiovascular risk factors and risk of death in diabetes. $J$ Endocrinol Invest 27: 175-181, 2004.

WEXLER BC, LUTMER RF: Adrenal glandular lipids and circulating corticosterone in severely diabetic rats. Br J Exp Pathol 56: 299-306, 1975.

WHEATLEY AM, BUTKOW N, GROTE J, MUSIKER J, ROSENDORFF C: The effect of propranolol, verapamil and dantrolene treatment on cardiac hypertrophy, enhanced myocardial contractility and tachycardia in the hyperthyroid rat. Pharmacol Res 22: 307-318, 1990.

YIN YL, PERRET GY, NICOLAS P, VASSY R, UZZAN B, TOD M: In vivo effects of amiodarone on cardiac betaadrenoceptor density and heart rate require thyroid hormones. J Cardiovasc Pharmacol 19: 541-545, 1992.

ZHANG Y, XIAO J, LIN H, LUO X, WANG H, BAI Y, WANG J, ZHANG H, YANG B, WANG Z: Ionic mechanisms underlying abnormal QT prolongation and the associated arrhythmias in diabetic rabbits: a role of rapid delayed rectifier $\mathrm{K}^{+}$current. Cell Physiol Biochem 19: 225-238, 2007.

ZIERHUT W, ZIMMER HG: Differential effects of triiodothyronine on rat left and right ventricular function and the influence of metoprolol. J Mol Cell Cardiol 21: 617-624, 1989.

ZOLA BE, MILLER B, STILES GL, RAO PS, SONNENBLICK EH, FEIN FS: Heart rate control in diabetic rabbits: blunted response to isoproterenol. Am J Physiol 255: E636-E641, 1988. 